\title{
CEREBRAL POLIOMYELITIS IN EARLY INFANCY
}

\author{
BY \\ VICTORIA SMALLPEICE and CHRISTOPHER OUNSTED
}

From the Children's Departments, the United Oxford Hospitals

The cerebral type of poliomyelitis, although described by Parsons and Barling (1933), is now seldom reported. The occurrence of this variant of the disease in infants seems to be excessively rare. All forms of poliomyelitis are, indeed, uncommon in early infancy (Mouton, Smillie, and Bower, 1950). This paper describes three infants, all probably infected from a common source, in whom the disease was followed by severe cerebral symptoms.

\section{Epidemiology}

The outbreak occurred in the late summer of 1947, a season now notorious for the virulence and extent of its epidemic poliomyelitis. The mise en scène was a private nursing home in a small town in Berkshire. All three patients were born in this home, within two months of one another. At no time was there, however, any direct contact between the children or between their families. A midwife, Sister J., was in contact with the first affected child (Case 1) three days before the onset of his illness. She subsequently had close contact with the other two affected children. She herself had no illness suggestive of poliomyelitis nor had any others among the staff of the nursing home. After the third patient had developed his illness the home was closed. Table I shows the timing of the outbreak as a whole.

\section{Case Reports}

Case 1.-The mother had had one previous, normal pregnancy. Her pregnancy with the patient was uneventful, and she carried him to term. She was admitted to the nursing home on the morning of July 19, 1947, and half an hour later was delivered spontaneously of a normal male child. The labour was attended by Sister J. The child's birth weight was $7 \mathrm{lb} .10 \mathrm{oz}$. ; he appeared quite healthy, cried at once, and sucked vigorously. He was given no injections of any kind.

The mother regained strength rapidly after delivery. She developed sore nipples on the tenth day and was advised to wean the child when she arrived home, which she did.

Mother and child left the nursing home, both in good health, on August 1, and went by car to stay at Henley

B 13 in a large and isolated house, where there were three young children aged 5 to 10 years. Shortly after their arrival, on August 6, the owner of the next farm developed poliomyelitis and died within 24 hours : there was no known contact between the two houses at the time.

Mother and child returned home on August 26. Both were well, and neither of them went out, except in their car, during the next four weeks.

The midwife (Sister J.), who had delivered the child, visited him at home on September 3. She played with the child and fed him from a bottle.

On September 6 the child suddenly became restless and irritable. He cried continuously and appeared to be in some pain. He is thought to have been feverish. $\mathrm{He}$ remained in this state for 24 hours. On September 8 he took an hour to suck $4 \mathrm{oz}$. of milk from the bottle, but otherwise appeared to be normal.

The next day, September 9 , he became very quiet and sleepy.

On September 10 the father developed a "cold" with malaise and fever, said to have been "just like a chill "'.

On September 11 the child's arms and legs were noticed to be limp and flaccid, he slept continually, was very slow with feeds, and seemed unable to cry. In the evening, in his bath, he suddenly gave a forced expiratory scream and went blue with lolling head. He recovered his normal colour and tone in a few seconds.

On September 13 he was seen by his family doctor. He was found now to be able to suck and cry normally : both legs and the right arm appeared to be wholly paralysed. The left arm was flaccid but some spontaneous movement was present. There were no other abnormal findings. The family doctor made a provisional diagnosis of poliomyelitis. On this day his elder brother developed a " chill" with malaise and headache.

$\mathrm{He}$ was seen in consultation (V.S.) on September 16 and the essential findings were as follows. The general condition was good : the cry was rather hoarse but strong. The lower left abdominal muscles were bulging and appeared paralysed but respiration was well maintained. The left arm appeared normal. The right arm was flaccid nor was there any movement at the shoulder. There was very slight flexion of the elbow and fingers, but none of the wrist, which was dropped. The right leg was completely flaccid, the only movement being an occasional twitching of the toes. There was slightly more tone in the left leg with a minimal contraction of the gastroc- 
TABLE I

THE TIME OF THE DISEASE IN THE THREE CASES

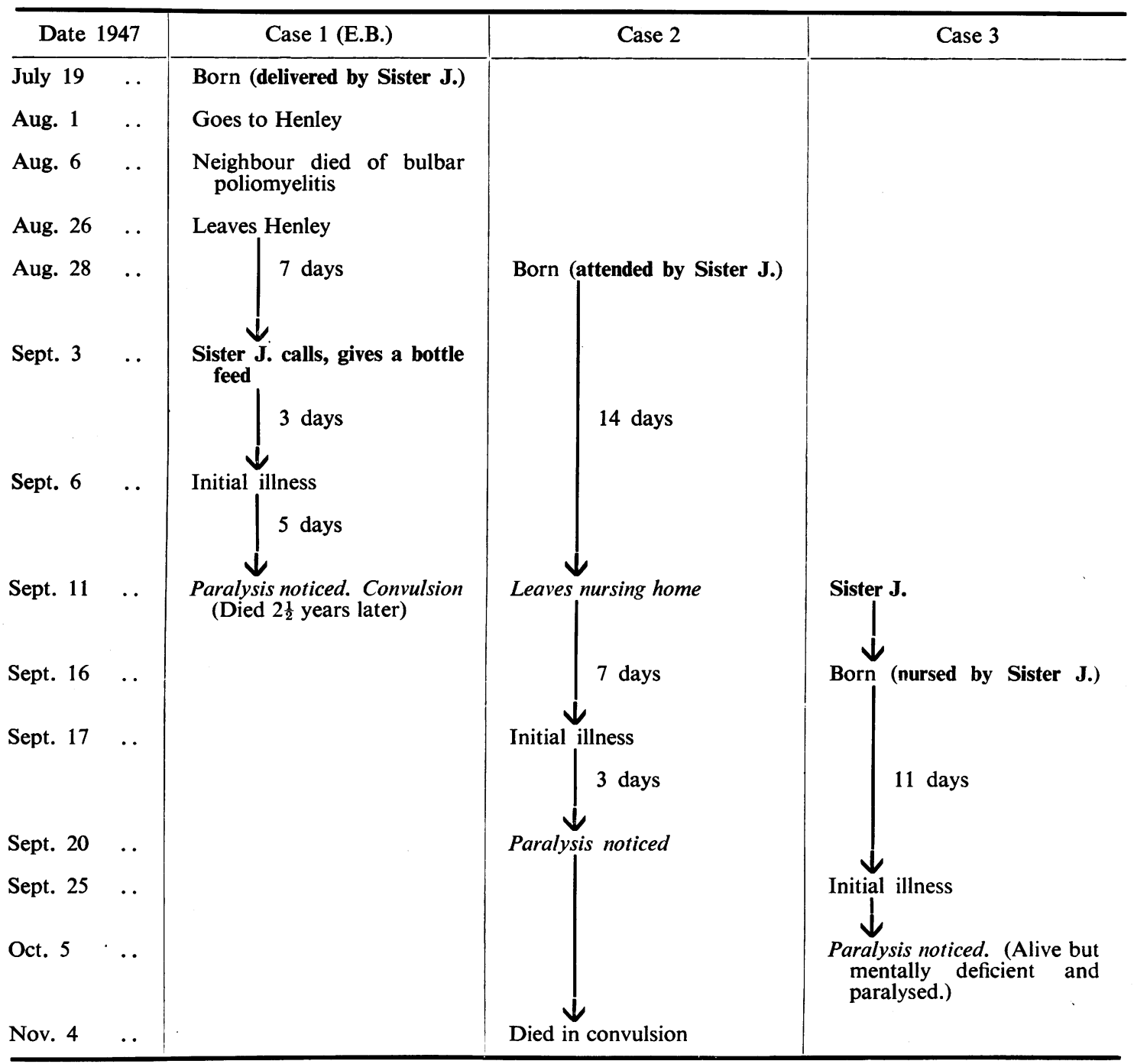

nemius on pricking the foot. There was a little power of extension both of the ankle and toes. Tendon reflexes were absent in both legs.

Other systems appeared to be healthy.

A presumptive diagnosis of poliomyelitis was made and the family was advised on the precautions necessary for isolation. Arrangements were made for the admission of the child for orthopaedic treatment at the end of the infectious period.

During the next few days the child's general condition improved rapidly, and the left arm was used more freely.

He was admitted to the Wingfield-Morris Orthopaedic Hospital on September 26. Examination showed little change from the findings on September 16. The diagnosis of poliomyelitis was accepted.

A lumbar puncture on September 28 gave a clear fluid under normal tension which contained $50 \mathrm{mg}$. of protein per $100 \mathrm{ml}$.; no white cells were seen. The paralysed muscles remained unchanged during the next six weeks whilst under observation in hospital.

From this time, until the child's death, he was under regular supervision. No recovery of power in the legs took place. The right leg rapidly became flail except for a flicker of movement in the plantar flexors ; subluxation of the right hip was found on January 21, 1949. In the left leg the flexors, abductors of the hip and 
quadriceps were wholly paralysed, but a flicker of movement in the plantar flexors remained. The muscles below the right knee remained unchanged. Paralysis of the left lower abdominal muscles remained unchanged; the muscles on the right recovered some power during the six months after his illness. The right arm muscles recovered their power within eight weeks of the onset of the illness with the exception of the right deltoid which remained permanently weak.

In March, 1948, the child had a brief convulsion in which he threw up the left arm, turned the head and eyes to the left and appeared to lose consciousness. There were four similar attacks during the next two years. On April 10, 1950, he had a more severe seizure in which he suddenly losi consciousness, went blue, and vomited copiously; there was no twitching of the limbs. $\mathrm{He}$ recovered in two minutes, but, during the remainder of the day had four more small seizures.

Shortly before his death, in April, 1950, he was adinitted to hospital for investigation.

Examination showed, in brief, a large, plump child with fair, curly hair and rounded features (Fig. 1). The child lay flat on his back, taking little notice of his surroundings, and making no sound except for an occasional grunt or roar. He made occasional aimless and ataxic movements of the arms, but did not attempt to play with toys. The grasp reflex was absent on both sides. Both legs were paralysed, the right being flail. Cranial nerves were normal, as were the fundi. Gross myopia was present. Examination of other systems showed no abnormality except for chronic infection and hypertrophy of the tonsils.

An electroencephalograph was made under seconal narcosis. A portion of the record is reproduced (Fig. 2), and it was reported as follows :-

"When recording started, he was drowsy and soon fell asleep. Almost continuously there were paroxysmal, very high voltage spikes, and slow wave complexes focusing in the left pre-central area, but occurring in the right hemisphere also.
These spikes became even more frequent as the 14 c./sec., "light sleep rhythm', appeared.

The record is grossly abnormal even for this age, and showed an almost continuous paroxysmal dysrh y th mia, similar to a subclinical pe $t$ i t $\mathrm{m}$ a 1 status, with an epilep togenic focus in the left pre-central region."

He was admitted to the Wingfie $1 \mathrm{~d}-\mathrm{M}$ or $\mathrm{r}$ is Orthopaedic

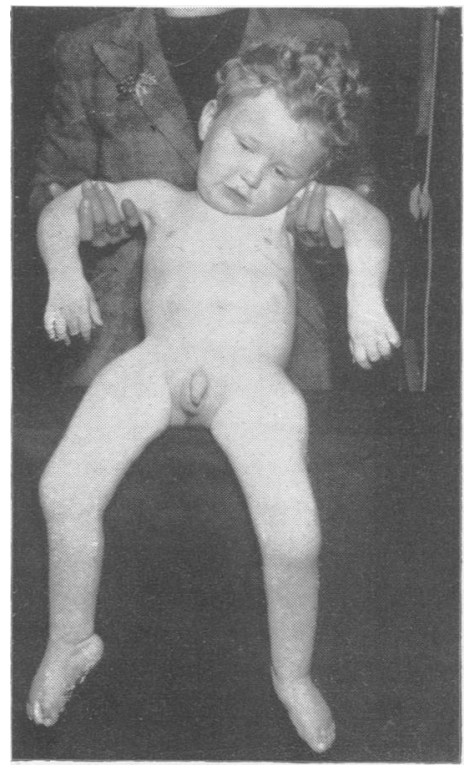

FIG. 1.-Case 1 shortly before death.
Hospital on April 26, 1950, under Professor J. Trueta, for the manufacture of a plaster bed, which was applied without difficulty under seconal sedation that evening.

The next day he had some difficulty with breathing and there were bronchitic rhonchi in the chest. At noon he appears to have had a mild fit. During the remainder of the day he was restless with slow and shallow respirations and slight cyanosis. At 8.30 p.m. he suddenly stopped breathing and died.

Necropsy.-Necropsy was performed by Dr. Peter Daniel and Dr. Dawn Bosanquet 37 hours after death.

The child's body was well covered. Wasting of the lower limbs was not obvious as there was plenty of fat

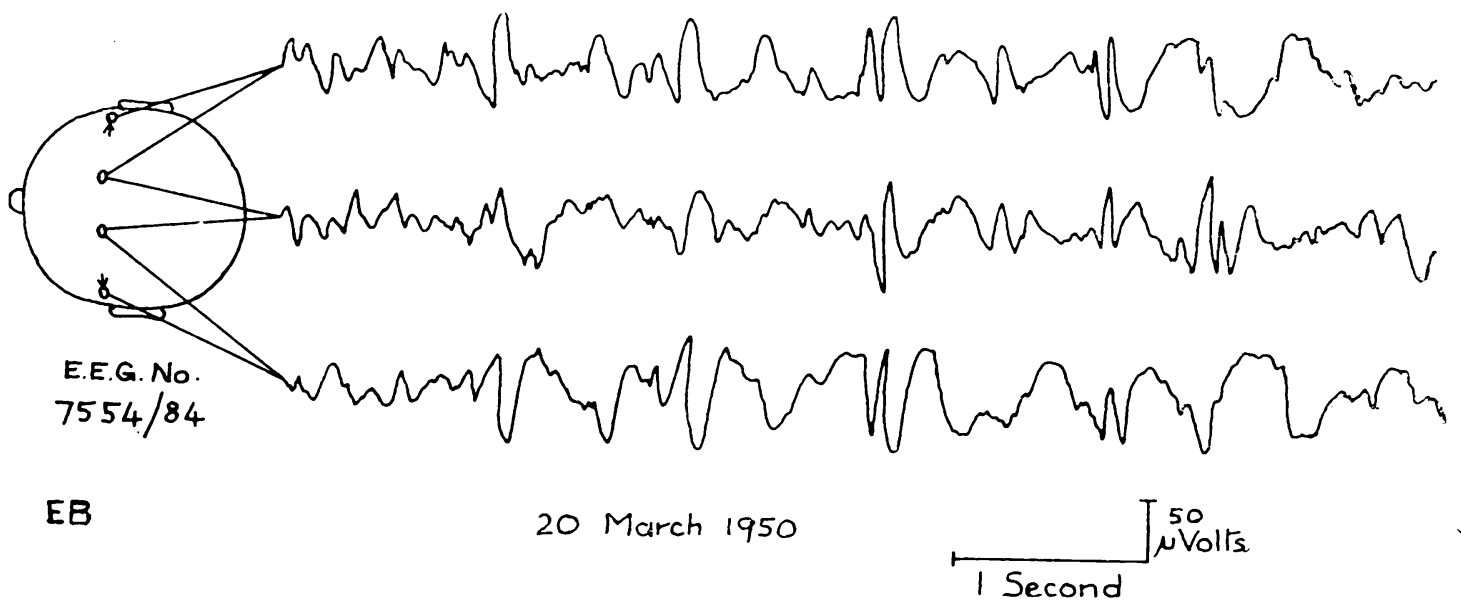

FiG. 2.-E.E.G. of Case 1 made shortly before death. 
on them, but palpation showed that wasting of the muscles was, in fact, extensive. Both feet were inverted, the right more than the left. The head was large and the forehead slightly bossed, otherwise there were no visible deformities.

Thorax.-The trachea and main bronchi, in their lower parts, contained brown aspirated vomit. The upper lobes of the lungs were normal, the lower lobes contained aspirated vomit in the smaller bronchi and were congested.

Skull.-The fontanelles were closed but very marked "thumb-markings" of the posterior half of the vault were obvious.

Dura.-The dura was not tense and the venous sinuses were not thrombosed.

Brain.-The frontal regions showed some convolutional atrophy but the parietal regions appeared normal. There was a considerable increase in fluid in the frontal sulci. The base of the brain was normal and there were no internal herniae. The basal vessels were in good condition. Coronal sections through the cerebrum showed no macroscopic abnormality.

Muscles.-All the muscles of the lower limbs were grey, resembling fish muscle, except for the upper part of the hamstrings and adductors. There was an unusually thick layer of fat on the limbs which masked the shrunken muscles. The muscles themselves did not look fatty. The diaphragm, intercostal, and back muscles looked normal, as did the muscles of the neck, tongue, and eye. In the arms, the forearm muscles and biceps looked normal, but the triceps was grey.

There was marked fatty change in the liver and kidneys. There were no abnormalities in other systems.

The immediate cause of death appeared to be the inhalation of vomitus.

Histology.-The histological examination was performed by Dr. J. G. Greenfield, who reported as follows.

The spinal cord was examined at the levels of C.5, C.8, mid-thoracic, lower thoracic, lower lumbar, and sacral segments. At C.5 the number of anterior horn cells was greatly reduced on one side and considerably reduced on the other. At C.8 virtually all the cells had disappeared on one side and only a few of the ventrolateral group remained on the other. In the middle and lower thoracic regions there was little abnormality except for a fairly dense gliosis in the anterior horns, by comparison with the rest of the grey matter of the cord. A similar gliosis was seen in the more affected segments of the cord. In the lower lumbar segments no nerve cells were seen in the anterior horn of one side and only four or five on the other side. At the sacral level the population of the antero-lateral group was normal, but very few cells were seen in the anteromedial group. These lesions evidently corresponded to an old poliomyelitis but there was now no evidence of inflammation.

There were no abnormalities to be found in the brain stem, cerebellum, or basal ganglia. The cortex was well laminated in all areas. The motor cortex was not identified, probably because the brain had already been cut into slices when received. But it is possible that failure to recognize it was due to disappearance or atrophy of Betz cells. There were numerous nerve cells in the subcortical white matter, but they were normal at this age. No cause for the mental retardation was found.

A post-mortem radiograph of the skull cap (Fig. 3) confirmed a remarkable degree of craniotabes in the occipital region. This was thought to be due to the sustained pressure of the head, for during life the child lay immobile upon his back and was seldom moved from the supine position.

This child developed his disease at the age of 7 weeks. The initial illness and the subsequent

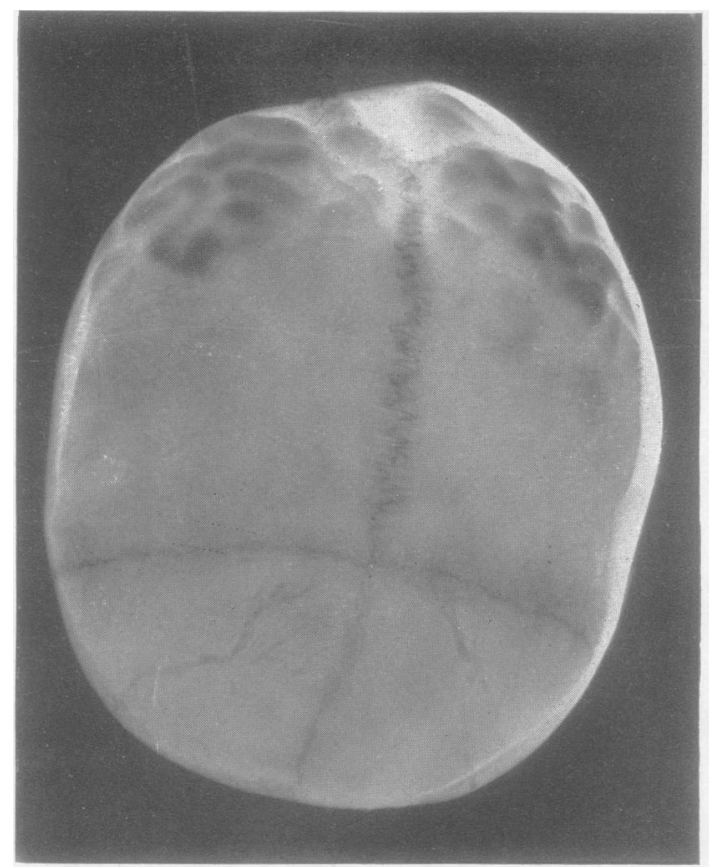

FIG. 3.-Radiograph (post-mortem) showing occipital craniotabes in E.B.

course of the lower motor neuron palsies were typical of spinal poliomyelitis. He later developed recurrent seizures with gross mental deficiency. At necropsy the changes in the spinal cord were those characteristic of an old poliomyelitis.

The other two patients are reported more briefly ; Case 2 was not seen by the authors.

Case 2.-R.A. was born in the same nursing home on August 28, 1947. The pregnancy and labour had been natural. The puerperium was without untoward events. The mother and child were attended by Sister J. There was a transient discharge from the child's nose and right eye at the age of 2 weeks.

At the age of 3 weeks he fell ill. He was feverish and appeared to be in pain, he cried continually and would 
often draw up his knees as though taken with colic. A few days later it was noticed that the right arm was weak and flaccid.

On October 11, 1947, he was admitted to an isolation hospital. He was found to be a well developed child, and apart from his right arm, was without abnormal physical signs. The right arm showed a complete paralysis of the deltoid, biceps, and triceps ; movements of the wrist and hand were normal. A lumbar puncture made on October 28 showed a pleocytosis of 140 cells per $\mathrm{ml}$. ( $26 \%$ polymorphs and $74 \%$ lymphocytes), but the fluid was heavily contaminated with blood.

The child continued in good health but without improvement in the paralysed muscles until November 3. On this day he had a convulsion with twitching of the face and deep cyanosis. He was put in an oxygen tent and the convulsion stopped. His temperature was found to be $102.8^{\circ} \mathrm{F}$.

The next day, at 3.30, the child had another convulsion and, during the convulsion, died.

Necropsy was refused.

This patient was not seen by the authors and we are indebted to Dr. T. Fisher for details of the case. The history and clinical findings conform with the diagnosis of poliomyelitis.

Case 3.-G.H. (R.I.95400/49) was born on September 16, 1947. The pregnancy had been natural but labour was three weeks premature. The child weighed $5 \mathrm{lb}$. $12 \mathrm{oz}$. at birth, he appeared quite healthy, sucked vigorously, and moved all his limbs. Sister J. was in attendance.

The mother was a healthy woman with one elder healthy child. There was no history of familial diseases. All was going well when, on September 25 , the child suddenly appeared lethargic and would not suck. The next day when seen in consultation he was ill with slight cyanosis, tachypnoea, and a temperature of $101^{\circ} \mathrm{F}$. The whole body was seen to be oedematous. Crepitations were present at both bases. The skull and fontanelle were normal; the neck and spine showed no stiffness. There were no paralyses. At the consultation it was decided to treat him as a case of bronchopneumonia and to give him a five-day course of intramuscular penicillin, and to feed him on expressed breast milk. He received 10,000 units of penicillin, intramuscularly, three-hourly. The injections were given into the thighs and deltoid muscles in rotation. On September 27 he was afebrile and appeared much better. On September 28 he had another peak of fever to $101^{\circ} \mathrm{F}$. which lasted for 24 hours; the generalized oedema was subsiding. Over the next few days the child's general condition rapidly improved, he regained vigour and sucked again with power. The left leg, however, lay flaccid, immobile, and oedematous.

Examination on October 7 showed that the left leg had in fact a complete flaccid paralysis of all muscle groups that could be tested. No other muscle groups were affected.

During the next few months the child progressed slowly and the left limb, in spite of a complete paralysis, grew normally in length. The child's general condition was good although it was noticed that he was tense and overactive.

During the latter part of his first year of life it was noticed that his hands were becoming useless. At the age of 8 months he had handled with ease a rusk, a rattle, and a doll: when he was 13 months old he was unable to grasp spontaneously and would drop a toy placed in his hands. At the same time spasticity began to appear in the right leg: this was first noticed at the age of 10 months as stiffness when the leg was handled. It was then seen that he did not move the leg spontaneously and that the toes were becoming clawed.

During this time he came under the care of Professor J. Trueta who observed that the child's mental development was grossly retarded. The child was on this account referred back to the Children's Department after an interval of one year and was admitted for investigation at the age of 16 months.

Examination on January 7, 1949, showed a retarded child unable to sit himself up. The tongue was constantly protruded and there was a continuous fine flickering movement of the orbicularis oculorum. The arms were held up, with clenched fists, and were constantly moving, very like a pugilist shadow-boxing. The thumbs were adducted. Both arms were spastic with increased tendon reflexes. The right leg also was spastic and the joints appeared stiff and painful on passive movement. The left leg was flail. No tendon reflexes could be elicited in the legs. The abdominal reflexes were absent.

Other systems showed no abnormal signs. Radiographs of the chest and skull were normal. The cerebrospinal fluid was clear and the cytology and biochemistry within normal limits. The blood picture was within normal limits. An electroencephalogram was reported thus: "There was a little unstable alpha rhythm at $8 \mathrm{c}$. $/ \mathrm{sec}$. on both sides. The record consisted mainly of runs of 5 to $6 \mathrm{c}$. $/ \mathrm{sec}$. with occasional episodes of 3 c./sec. at medium voltage. These episodes started on the left side frontally, and then became bilaterally synchronous. The record was abnormal for this age, and the bi-frontal $3 \mathrm{c}$. $/ \mathrm{sec}$. activity, starting on the left, may be a peit mal variant, although no typical waveand-spike was seen."'

Shortly after his admission he developed septicaemia due to Bact. coli. This illness ran a prolonged course, but was eventually controlled with sulphamezathine. He was taken home on February 13, 1949.

On April 17, 1950, he was re-examined. His mother thought that both his mental condition and his paralyses had remained unchanged during the past 14 months. He had had occasional "lapses", in which the flow of movement stopped suddenly, he stared, twitched his face, and then resumed his usual activity. These attacks had been variable: sometimes he had had several a day and at other times none for periods of several weeks. There had been no major seizures. His appetite was excessive and he appeared to be wholly impervious to cold. On examination, the condition of the child appeared to be static. His behaviour pattern was unchanged. He did not speak or show interest in his surroundings. He sat propped up making coarse 
athetoid movements of the arms. His grimaced constantly and gibbered vigorously. When given a spoon he perseverated on a simple banging movement against the side of his pram. The left leg was unchanged, remaining flail, wasted, and immobile. There was, however, no shortening compared with the right leg. The arms and right leg showed no change from their condition a year before.

Other systems showed no abnormal signs.

This child had what appeared to be a simple attack of spinal poliomyelitis shortly after birth involving the left leg. He later developed spastic paralysis of the remaining leg and both arms with gross hyperkinetic mental deficiency, athetosis, and recurrent minor epileptiform seizures.

\section{Discussion}

Epidemiology.-The first six months of life are generally considered to be a period of marked immunity to poliomyelitis. Between 1897 and 1948 only 17 such cases appear in the literature. It is remarkable, therefore, that Mouton and others, (1950) were able to find 10 cases in a single epidemic. Many other reports of single cases have in fact been published recently (Garlick, 1948 ; Brandt, 1946 ; Biermann and Piszczek, 1944; Shelokov and Weinstein, 1951). The disease in several of the cases derived from the mother. Shelokov and Weinstein suggest that in their case the transmission of the virus occurred in utero. The majority of women affected with poliomyelitis at term, however, give birth to healthy children.

We have suggested that the midwife, who attended the three children described in this paper, was the vector. She was entirely healthy throughout the whole episode. Adamson, Moody, Peart, Smillie, Wilt, and Wood (1949), in their elegant study of the ecology of poliomyelitis among the Arctic Eskimo, have shown that the clinically healthy human carrier is the chief vector of the disease. Sweetnam (1948) has given evidence of this mode of spread in England; Hahn and Taylor (1947) arrived at similar conclusions for a German epidemic, as did Nissen (1947) for the St. Helena outbreak. In our cases the midwife was the only person to have contact with all the affected children. It appears probable that the virus entered the family of E.B. (Case 1) at Henley and was manifested in E.B. as florid poliomyelitis and in his father and brother as an abortive febrile illness. The midwife may have acquired the virus at her visit on September 3 (Table 1), and may later have transferred the disease to the other two children. The evidence is necessarily wholly circumstantial. If indeed this was the route of the disease the incubation periods were of the order: Case 1, 10-30 days; Case 2, 7-14 days ; Case 3, 9 days or less.
Clinical Features.-The syndrome of " cerebral " poliomyelitis finds little place in the recent literature, although it is mentioned by Wickman; and the syndrome, as it appeared in our patients, was described in full by Parsons and Bareing (1933).

Bodian (1947), in his classical study, showed that widespread encephalitic foci were invariably found in patients who died in the acute phase of the disease, and he remarked that, to the pathologist, both experimental and human poliomyelitis were invariably encephalitic. Clinical signs of cortical dysfunction were shown by Brown, Baker, Adams, and McQuarrie (1947) to be common in the acute phase of the bulbar variant. They found that these symptoms resolved when oxygen was given and concluded that they arose largely from cerebral anoxia. Crothers and Meyer (1946), in a psychological assessment of 15 children who had had encephalitic signs in the course of poliomyelitis, found in all cases some minor mental disturbance, usually taking the form of visuomotor deviations.

There appears to be little doubt that the poliomyelitis viruses may cause both pathological and clinical lesions at any level of the cerebrospinal axis. Clinically manifest lesions above the level of the cord are, however, transient in the vast majority of patients.

The three children we have described presented in the initial stages with acute biphasic febrile illnesses, followed by multiple lower motor neuron palsies, and appeared to have the simple spinal type of the disease. This was followed, however, in the two survivors by the slow unfolding of the signs of mental retardation with epileptic seizures. Brewis and Neubauer (1948) have described a girl of $17 \frac{1}{2}$ who, in the course of polioencephalomyelitis had convulsions, but this complication is excessively rare. Mouton and others (1950) found no case of convulsions during the acute phase of poliomyelitis in infancy either in their own series or in the literature ; they did not, however, present the results of a follow-up study of their cases. Mental deficiency is notoriously elusive in the first year of life, whilst epilepsy commonly matures silently between a primary insult and the onset of seizures. Both these features were apparent in our patients. Convulsions occurred in all three and in two cases were directly associated with the death of the children. In Case 2 there was a lapse of 46 days between the onset of the poliomyelitis and the child's death during a convulsion. In Case 1 death followed some hours after a seizure, and seemed to have been due to the inhalation of vomit while the child was unconscious. This child's epilepsy appeared seven months after the acute phase of the disease. In Case 3 minor epileptiform seizures appeared in the third year of 
life. The lesions underlying the gross mental deficiency of these children were not defined, and at necropsy the brain of E.B. showed neither gross nor microscopic evidence of cerebral destruction on sectioning. On the other hand, the electroencephalographic records showed severe abnormalities, and presented in Case 1 a pattern resembling the status of petit mal. It is interesting to speculate upon the role of the chronic electrical dysharmony as a causal factor in the dementia of these children.

One final point should be mentioned. The diagnosis of poliomyelitis in the preparalytic phase is a matter of extreme difficulty in early infancy. The ordinary physical signs of meningeal irritation are often absent in affected infants, (Mouton and others, 1950) and these signs were absent in the children in the present study. Similarly, neck rigidity is usually absent in neonatal meningitis (Jackson, 1950). Unexplained fever with lethargy and pain on fondling, or enlargement of the skull, demand diagnostic lumbar puncture at this age.

\section{Summary}

A small outbreak of poliomyelitis in a nursing home is described.

The patients were infants of 7,3 , and 2 weeks of age. All had multiple lower motor neuron palsies. One died in convulsion during the convalescent phase of the disease. One child survived for two years and nine months but was affected with multiple palsies, idiocy, and fits. He died after a seizure and showed at necropsy the typical lesions of poliomyelitis in the spinal cord. One child remains alive but is also an epileptic idiot with upper and lower motor neuron palsies and athetosis.

The epidemiological and clinical aspects of the syndrome are discussed.

We wish to express our gratitude to Dr. J. G. Greenfield for making a histological study of Case 1, and to Drs. Peter Daniel and Dawn Bosanquet for the necropsy report. We are indebted to Dr. T. Fisher for the details of Case 2 , and to Professor $\mathbf{J}$. Trueta for permission to quote his observations on Cases 1 and 3.

\section{REFERENCES}

Adamson, J. D., Moody, J. P., Peart, A. F. W., Smillie, R. A., Wilt, J. C., and Wood, W. J. (1949). Canad. med. Ass. J., 61, 339.

Biermann, A. H., and Piszczek, E. A. (1944). J. Amer. med. Ass., 124, 296.

Bodian, D. (1947). Ibid., 134, 1148.

Brandt, S. (1946). Ugeskr. Laeg., 108, 265.

Brewis, E. G., and Neubauer, C. (1948). Brit. med. J., 2, 416.

Brown, J. R., Baker, A. B., Adams, J., and McQuarrie, I. (1947). J. Amer. med. Ass., 134, 757.

Crothers, B., and Meyer, E. (1946). J. Pediat., 28, 324.

Garlick, C. H. (1948). N. Z. med. J., 47, 599.

Hahn L., and Taylor I. (1947). Med. Offr., 78, 181.

Jackson, W. P. U. (1950). Arch. Dis. Child., 25, 22.

Mouton, C. M., Smillie, J. G., and Bower, A. G. (1950). J. Pediat., 36, 482.

Nissen, K. I. (1947). Proc. roy. Soc. Med., 40, 923.

Parsons, L. G., and Barling, S. (1933). "Diseases of Infancy and Childhood," vol. 2, p. 1253. London.

Shelokov, A., and Weinstein L. (1951). J. Pediat., 38, 80.

Sweetnam, W. P. (1948). Brit. med. J., 1, 1172. 